\title{
Hold-time effect on the thermo-mechanical fatigue crack growth behaviour of Inconel 718
}

\author{
Johan Moverare and David Gustafsson
}

\section{Linköping University Post Print}

N.B.: When citing this work, cite the original article.

Original Publication:

Johan Moverare and David Gustafsson, Hold-time effect on the thermo-mechanical fatigue crack growth behaviour of Inconel 718, 2011, Materials Science \&amp; Engineering: A, (528), 29-30, 8660-8670.

http://dx.doi.org/10.1016/j.msea.2011.08.027

Copyright: Elsevier

http://www.elsevier.com/

Postprint available at: Linköping University Electronic Press

http://urn.kb.se/resolve?urn=urn:nbn:se:liu:diva-71304 


\title{
Hold-time effect on the thermo-mechanical fatigue crack growth behaviour of Inconel 718
}

\author{
Johan J. Moverare ${ }^{1,2}$, David Gustafsson ${ }^{3, *}$ \\ ${ }^{1}$ Division of Engineering Materials, Department of Management and Engineering, \\ Linköping University, SE-581 83 Linköping, Sweden \\ ${ }^{2}$ Siemens Industrial Turbomachinery AB, SE-61283 Finspong, Sweden \\ ${ }^{3}$ Division of Solid Mechanics, Department of Management and Engineering, \\ Linköping University, SE-581 83 Linköping, Sweden
}

\section{Abstract}

In-phase TMF crack growth testing with different lengths of the hold time at the maximum temperature of $550^{\circ} \mathrm{C}$ has been conducted on Inconel 718 specimens. Focus has been on establishing a method for TMF crack growth testing and investigating the effect of high temperature hold times on the TMF crack growth of the material. The tests are compared to isothermal crack propagation tests and show good correlation. It is concluded that the controlling effect of the crack growth is an embrittlement of the material. This embrittlement is related to the concept of a damaged zone active in front of the crack tip. The size of this damaged zone will control the crack propagation rate and therefore it does not matter if the load is cycled under isothermal or TMF conditions.

Keywords: Thermo-mechanical fatigue, dwell time effects, Inconel 718

\section{Introduction}

The nickel-based superalloy Inconel 718 is extensively used as a structural material in gas turbines for industrial and aerospace applications. This is due to the combination of superior mechanical properties at elevated temperatures and excellent corrosion and oxidation resistance. Normally, this type of material is subjected to rather complex stress and temperature cycles due to the temperature gradients that occur during engine start-up and shut-down or from temperature gradients within the component during steady-state operation. The accumulation of such stress and temperature cycles leads to the possibility of failure by thermo-mechanical fatigue (TMF), which must be avoided by appropriate design of the component and choice of operating conditions. The service life of many hot components is not fully restricted by the number of cycles to crack initiation since, especially close to stress concentrations, one can also rely on stable and predictable crack propagation, which means that one can allow certain amount of crack propagation before the component has to be replaced in service. However, such damage tolerant approaches demand accurate predictions of the crack growth under the influence of simultaneous cycling of temperature and mechanical loads. Although methods have been developed to predict crack growth rates under isothermal conditions over a wide range of temperatures, frequencies and load ratios, as well as under sustained load dwell times, only very few published studies on crack propagation under TMF conditions are available. Furthermore, since the translation of iso-thermally obtained fatigue crack propagation data into a true thermo-mechanical fatigue context is questionable, the need for more experimental studies in this field is obvious. 
Unfortunately, mechanical testing under dynamic temperature conditions is somewhat more complex than other more traditional iso-thermal testing techniques. The pioneering work in this field where conducted by Leverant and co-workers at Pratt \& Whitney Aircraft in the 70'ies [1-3] when the influence of oxidation-resistant protective coatings on fatigue crack initiation as well as on propagation of coating-initiated cracks into the superalloy substrate were studied. The approach was based on the combination of a specimen design and testing method that could simulate the various straintemperature phase relationships experienced in turbine airfoils, including measurement of thermo mechanical fatigue crack growth. The testing was conducted under mechanical strain control using tubular specimen with through-thickness circumferential cracks. The temperature cycle was provided by induction heating and an optical method was used for the measurement of the crack lengths. A similar approach was later used by Okazaki and Koizumi [4, 5] in order to study the TMF crack propagation behavior in several different types of steels. In other studies, rectangular single-edge notch specimens (SEN) or double-edge notch specimens (DEN) have been used in combination with the potential drop technique for crack length measurements [6-10]. Alternative heating methods have also been used, like quartz lamps for the heating of standard compact tension (CT) specimens [11-13] or by the flow of hot air through a nozzle directed toward the sample [14]. Both of the techniques for measuring cracks lengths mentioned above are sensitive to thermal gradients and variations in temperature. Since the electrical conductivity changes with temperature, the potential drop technique will be sensitive to thermal gradients. In addition disturbances in the PD signal may occur due to the high frequency electromagnetic field generated by the induction heating coil. Optical techniques are limited to the surface of the specimen while it is preferable to have through thickness information of the crack length. In addition the optical techniques are sensitive to the illumination conditions on the specimen.

Even if both the academic and industrial need for non-isothermal testing is high, there exists no standard or common practice for conducting fatigue crack propagation testing under TMF conditions. Therefore, in this study we intend to show that it is possible to explore the TMF crack propagation behaviour using an experimental set-up which is only slightly modified compared to that typically used for crack initiation studies on smooth specimens as outlined in the European code of practice [15]. Furthermore, the dramatic effect of introducing hold times in tension at elevated temperature is also studied. The obtained results are of importance in that they contribute to the experimental basis and understanding of TMF crack growth in superalloys in general and in Inconel 718 in particular, and thus open up the possibility of successful modelling of the observed phenomena.

\section{Method}

As mentioned previously, the wrought nickel-based superalloy Inconel 718, one of the most commercially used alloys for gas turbines and aero engines, is in focus of this study. The chemical composition is Ni-17.9Cr-3.0Mo-0.50Al-1.0Ti-5.5Nb-16.9Fe (wt.\%). The material used was taken from a turbine disc forging that was solution heat treated and aged according to the AMS 5663 standard and has a grain size corresponding to ASTM 10 to 12. 
A single-edge notched specimen was used for the experiments, see Figure [1]. The specimen has a rectangular cross section with a thickness of $3 \mathrm{~mm}$ and a total width of $12 \mathrm{~mm}$. On one side of the specimen, a $3 \mathrm{~mm}$ deep notch is present which has a notch radius equal to $1.0 \mathrm{~mm}$. This notch is very blunt compared to a fatigue crack but is instead representative for the type of stress concentrations that are commonly found in real structural components. Since no other type of precrack was applied to the specimens prior to the testing, a significant portion of the fatigue cycles were actually spent on the initiation of a TMF crack from this stress concentration. The reason for conducting the testing in this manner is that the deformation structures produced in nickel-based superalloys might have significant influence on the crack path. This has recently been illustrated for single crystal nickel-base alloys [16].
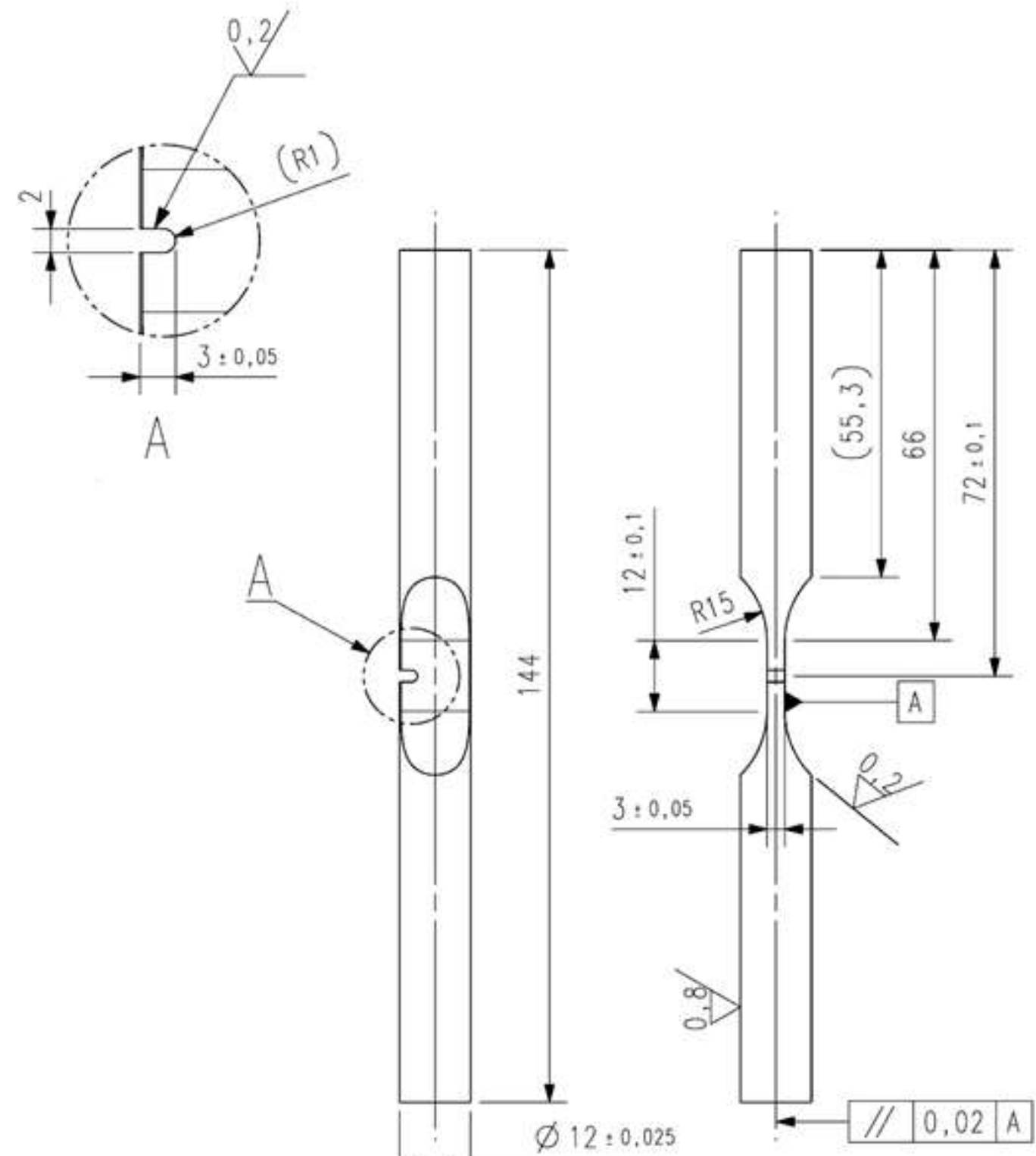

Figure 1: Specimen Geometry

In phase (IP) thermo-mechanical fatigue cycling were conducted under mechanical strain control in the $50-550^{\circ} \mathrm{C}$ temperature range using a MTS 810 servo-hydraulic thermo-mechanical fatigue machine. An extensometer with a 12-mm gauge length was 
symmetrically attached to the specimen over the notch as seen in the experimental setup in Figure [2]. All tests were conducted in displacement control by prescribing the displacement of the extensometer gauge length. In this paper the displacement measured by the extensometer $(\Delta L)$ divide by the extensometer gauge length $\left(L_{0}\right)$ will be referred to as the nominal total strain $\varepsilon_{t o t}^{n o m}=\Delta L / L_{0}$. In order to have control of the nominal mechanical strain $\varepsilon_{\text {mech }}^{\text {nom }}$ it is necessary to compensate for the axial displacement induced in the specimen due to thermal cycling. Therefore the thermal displacement measured by the extensometer $\varepsilon_{t h}^{n o m}$ must be substracted from the measured nominal total strain $\left(\varepsilon_{\text {mech }}^{\text {nom }}=\varepsilon_{\text {tot }}^{\text {nom }}-\varepsilon_{t h}^{\text {nom }}\right)$. The thermal displacement were measured under zero load control for each specimen prior to the test and for reason of simplicity it is assumed that the nominal thermal strain is unaffected by the crack growth. In the rest of the paper the nominal mechanical strain range is used to define the test condition applied. However, it must be remembered that the strain is not uniform along the gauge section due to the notch. Furthermore all tests were performed with a nominal mechanical strain ratio of $R=\varepsilon_{\text {mech,min }}^{\text {nom }} / \varepsilon_{\text {mech,max }}^{\text {nom }}=0$. To enable thermal cycling, induction heating has been used in combination with convection cooling from compressed air distributed onto the specimen by two cooling nozzles as seen in Figure [2]. The induction coil was designed in such a way that during heating, the main part of the heat input occurs at the shoulders of the specimen outside the gauge section of the specimen. This is illustrated in Figure [3] where one can see the dynamic temperature distribution in the mid-section of the specimen at a temperature of approximately $360^{\circ} \mathrm{C}$ and a constant heating rate of $1{ }^{\circ} \mathrm{C} / \mathrm{s}$ as recorded using a thermal imaging system from Flir. Similar measurements were also performed under static conditions in order to measure the temperature distribution during a hold time at $550^{\circ} \mathrm{C}$. It was found that one can achieve a temperature gradient in the flat gauge section of the specimen which is always less than $15^{\circ} \mathrm{C}$ if the heating and cooling rates are sufficiently low. As a consequence all tests have been conducted with a constant heating and cooling rate of $1{ }^{\circ} \mathrm{C} / \mathrm{s}$, which was found sufficiently low. In order to examine dwell time effects on TMF crack propagation, hold times of either 0,5 or 360 minutes were applied at the maximum strain and temperature in some of the tests.

In this study the guidelines in ASTM E 647-08 for measurement of fatigue crack growth rates under iso-thermal conditions using the compliance method have been adopted [17]. In this method the nominal stress $\sigma_{\text {nom }}$ (defined as the applied force divided by the net cross section of the un-cracked specimen) versus the nominal mechanical strain $\varepsilon_{\text {nom }}$ (defined as the mechanically but not the thermally induced displacement measured by the extensometer over the notch divided by the extensometer gauge length) is plotted. As seen in Figure [4], the slope in the tensile part of the nominal stress-strain curve will decrease as the crack becomes longer. By combining optical measurements of the crack length during a number of experiments with careful examinations of the corresponding fracture surfaces, a relationship between the change in stiffness and the crack length has been established. For the current configuration of specimen geometry, material and temperature range, the following relationship can be used to determine the crack length $a_{i}$ for cycle $N_{i}$

$$
a_{i}=4,9488 \cdot\left(1-\frac{M_{N_{i}}}{M_{\text {uncracked }}}\right)
$$




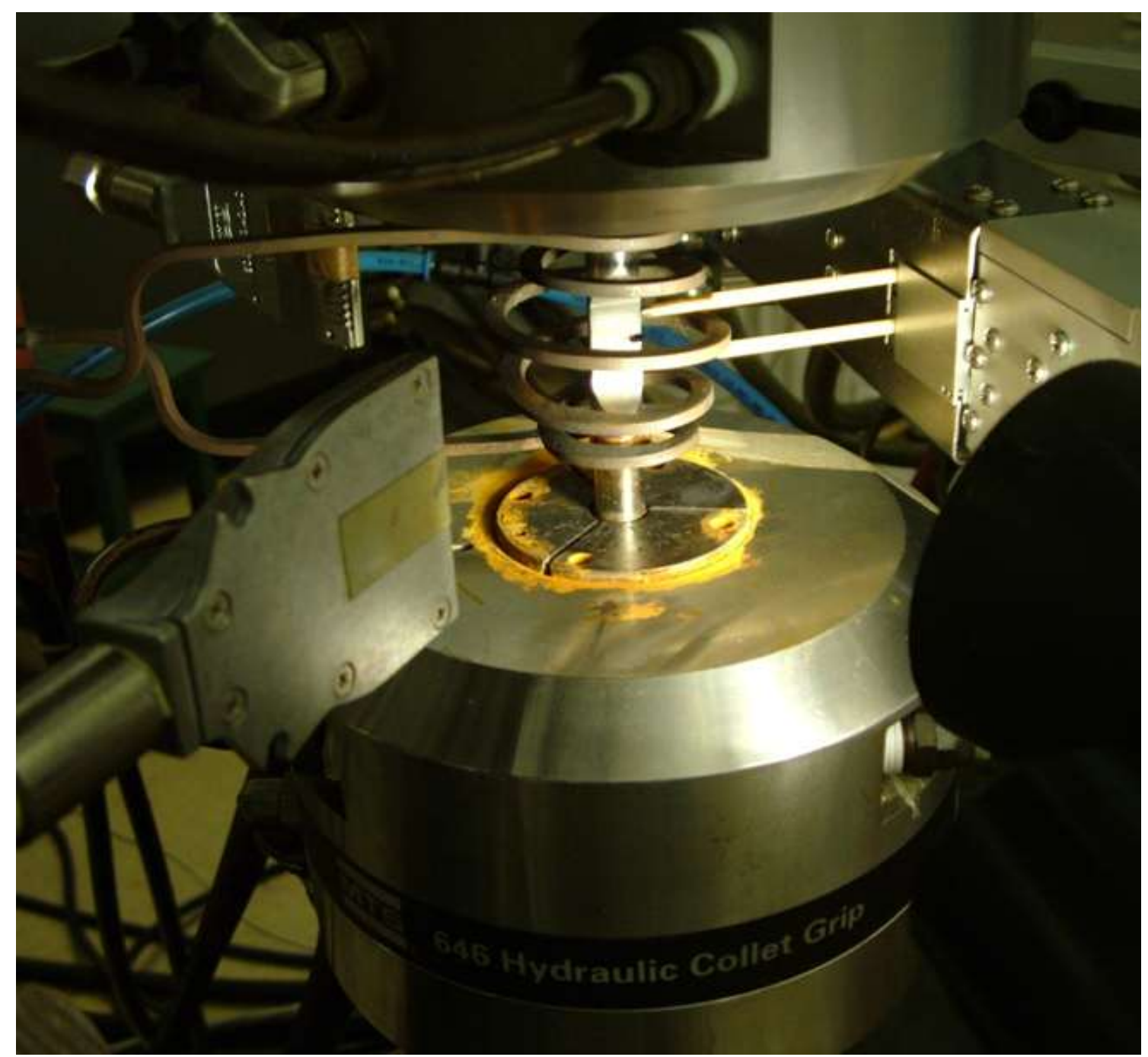

Figure 2: Experimental set-up

where $M_{N_{i}}$ and $M_{\text {uncracked }}$ are the slopes in the tension part of the nominal stress-strain loop at cycle $N_{i}$ and at an uncracked condition, respectively. The stiffness has for the latter case been evaluated as the average of several cycles in the beginning of the test when no crack is present. The simple relationship described by Equation (1) provides an excellent opportunity to calculate the crack length for every individual cycle in all tests in a very simple and straight forward way, which is less time consuming compared to the optical method. Finally, each test specimen are examined after testing. Each final crack length are compared to the relationship described by Equation (1).

The stress intensity factor $\mathrm{K}_{\mathrm{I}}$ as a function of load and crack length has been calculated using the Trinitas software developed at Linköping University [18]. Since the specimen has two symmetry planes one-quarter of the specimen was modelled in 3D using solid Lagrangian 27-node brick and 18-node wedge elements, see Figure [5]. In the model a semi-circular crack shape was defined by a Bèzier spline along which the stress intensity factors were calculated for each node by considering the energy release rate from a virtual crack extension of the crack tip nodes.

After the testing, the fracture surfaces of the ruptured specimens were examined using scanning electron microscopy (SEM). Some of the tests were interrupted before 
complete fracture occurred and transverse cross sections of the corresponding cracks were prepared by the usual metallographic procedures (cutting, grinding and mechanical polishing). The SEM study was performed using the backscatter mode in an analytical SEM, Hitachi SU70 operating at $20 \mathrm{kV}$. No etching was performed on the samples and the contrast was achieved from differences in composition and crystallographic orientation only.

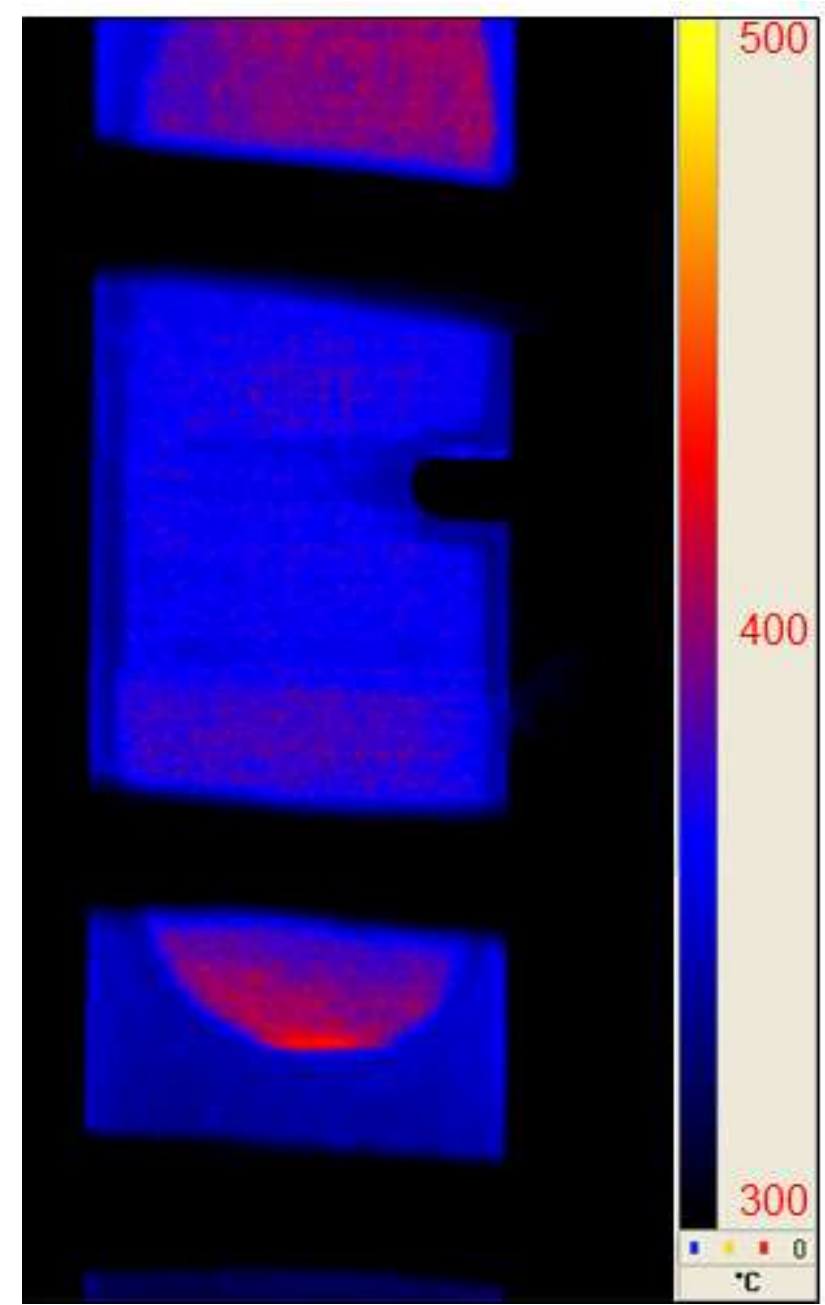

Figure 3: Temperature distribution at $380^{\circ} \mathrm{C}$ during heating with $1^{\circ} \mathrm{C} / \mathrm{s}$

\section{Results}

\subsection{Mechanical testing}

In-phase TMF testing between 50 and $550^{\circ} \mathrm{C}$ were performed in mechanical strain control, with different strain ranges and different lengths of the dwell time at the maximum temperature. In Figure [6], the crack length is plotted as a function of fatigue cycles for all tests with no or 5 min dwell time. In general the crack propagation rate is decreased with decreasing nominal strain range. In addition to the above mentioned tests, two tests were performed where partly a significantly longer dwell time was introduced. The tests were started without any hold time and when a crack had initiated and propagated to a certain length, the TMF cycle was changed and a 360 min dwell time was introduced. The results from these tests can be seen in Figure [7]. The crack propagation rate has been evaluated by fitting a $4:$ th order polynomial to the data in 
Figure [6] and Figure [7] and the rate is then simply calculated as the derivative of that function. The results from all tests are summarized in Table 1.

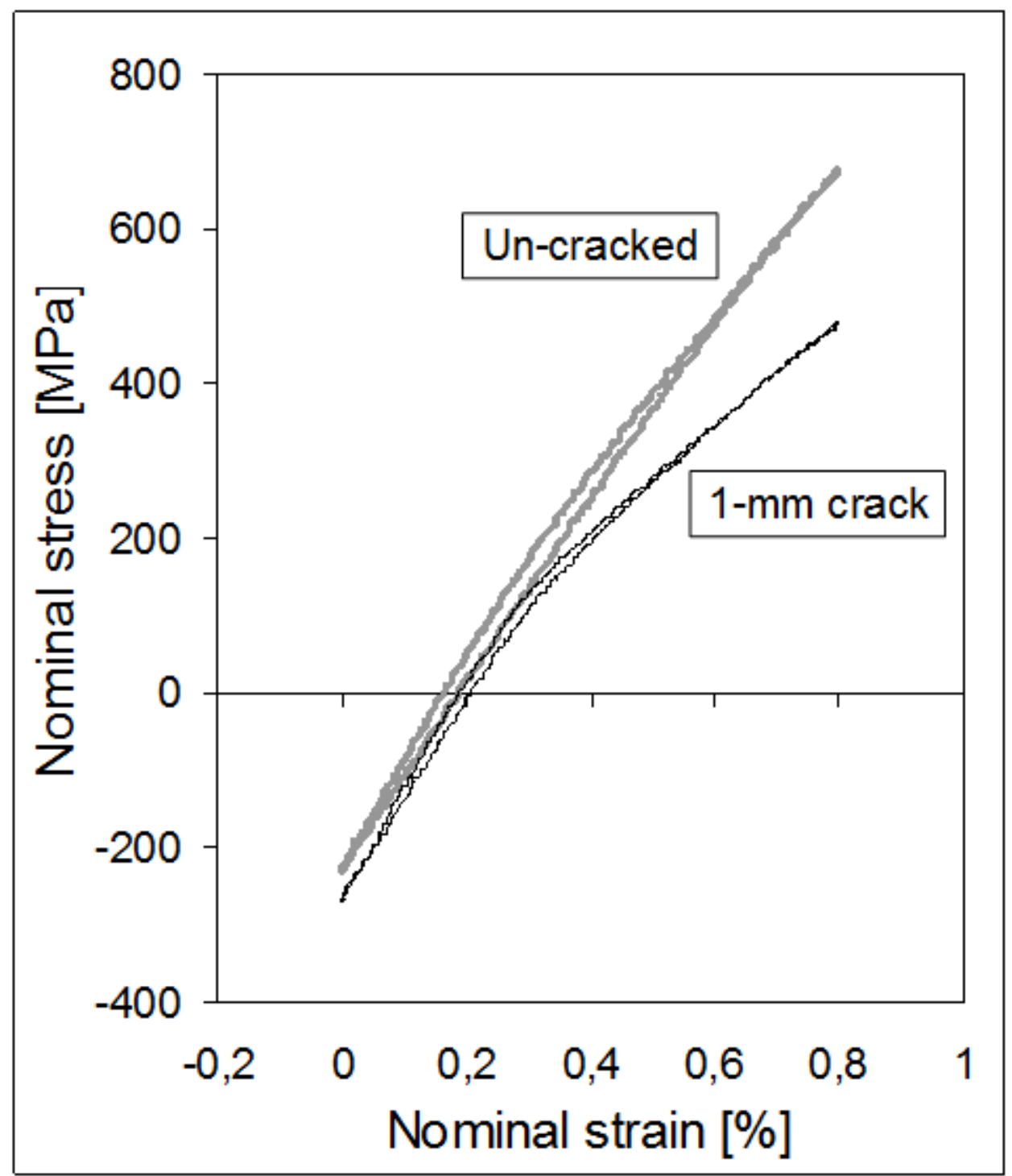

Figure 4: Plot of the nominal stress $\sigma_{\text {nom }}$ (defined as the applied force divided by the cross section of the un-cracked specimen) versus the nominal strain $\varepsilon_{\text {nom }}$ (defined as displacement measured by the extensometer over the notch divided by the extensometer gauge length)

As indicated in Table 1 the introduction of a 360 min dwell time in tension at maximum temperature leads to a dramatic increase in the TMF crack propagation rate. This is also illustrated in Figure [8].where the crack propagation rate at a nominal strain range of $0.7 \%$ is plotted for three different dwell times.

Since all tests are conducted in mechanical strain control, the strain range is the same for all cycles in the test, while the maximum and minimum nominal stress will vary depending on the amount of plasticity in the first cycle and the length of the growing crack. In addition to the maximum and minimum nominal stress in each cycle, also the crack closure level has been evaluated. As seen in Figure [9], a clear change in slope of the nominal stress strain curve can be seen and by fitting a straight line to the upper and 
lower part of the curve, the intersection of these curves defines the crack closure level in the present work. As an example, the evolution of the nominal stress range, maximum and minimum nominal stress and the crack closure level are plotted in Figure [10] as functions of the number of cycles for a test with a strain range of $0.8 \%$ and a $5 \mathrm{~min}$ dwell time.
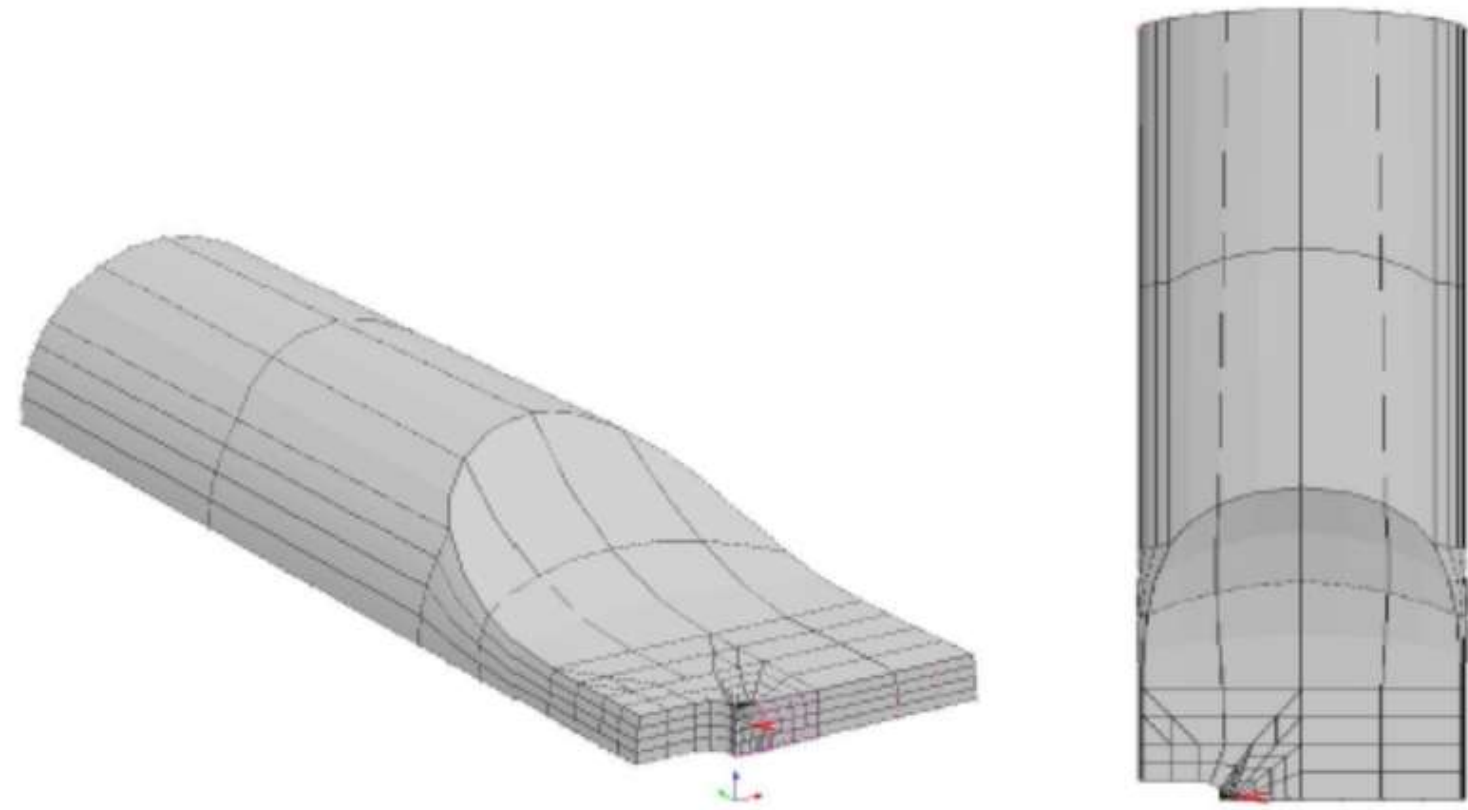

Figure 5: Finite element model in 3D of one-quarter of the specimen
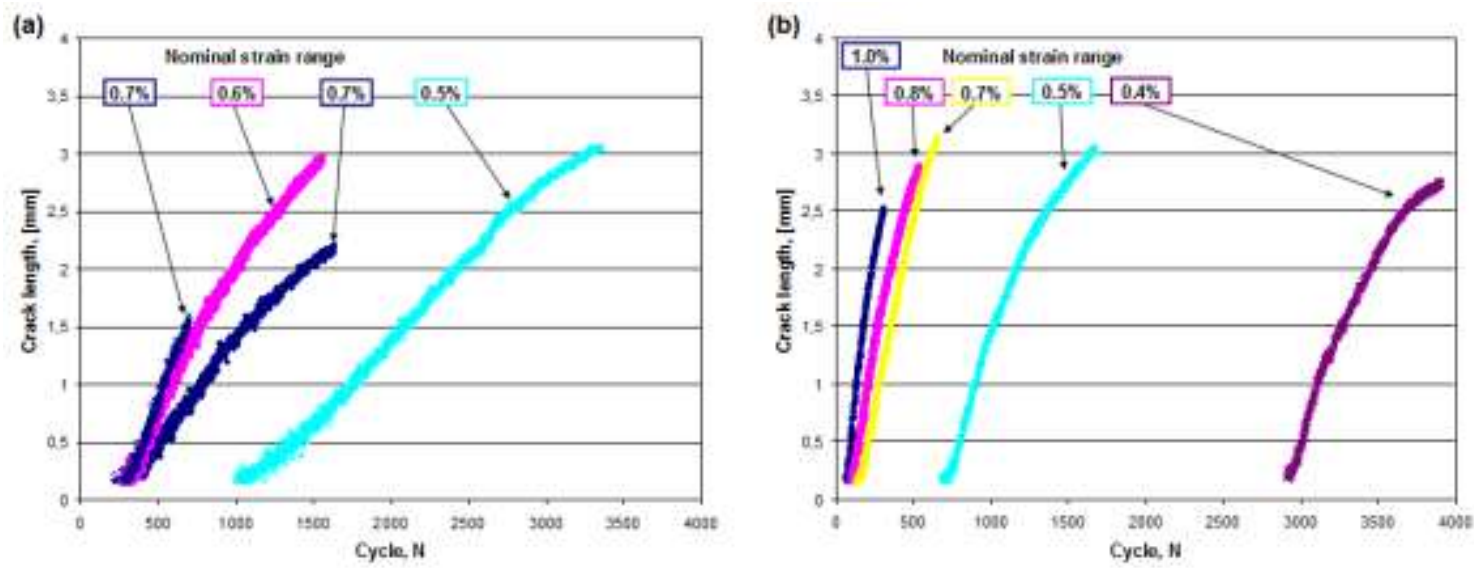

Figure 6: Crack length versus fatigue cycles for (a) tests with no dwell time and (b) tests with 5 min dwell time in tension at maximum temperature.

\subsection{Calculation of stress intensity factor}

Using the finite element model seen in Figure [5], the stress intensity factor has been calculated as a function of the applied load (described by the nominal stress) and the crack length. The crack propagation rates have then been correlated to a Paris law type expression based on either the stress intensity factor range $\Delta K_{\mathrm{I}}$ as described by Eq.(2) or the maximum stress intensity factor $K_{\max }$ as described by Eq.(3);

$$
\begin{aligned}
& \Delta K_{\mathrm{I}}=f(a) \cdot\left(\sigma_{\text {max }}^{\mathrm{nom}}-\sigma_{\text {close }}\right) \cdot \sqrt{\pi \cdot a} \\
& K_{\max }=f(a) \cdot \sigma_{\text {max }}^{\mathrm{nom}} \cdot \sqrt{\pi \cdot a}
\end{aligned}
$$$$
\text { Eq. } 2
$$ 


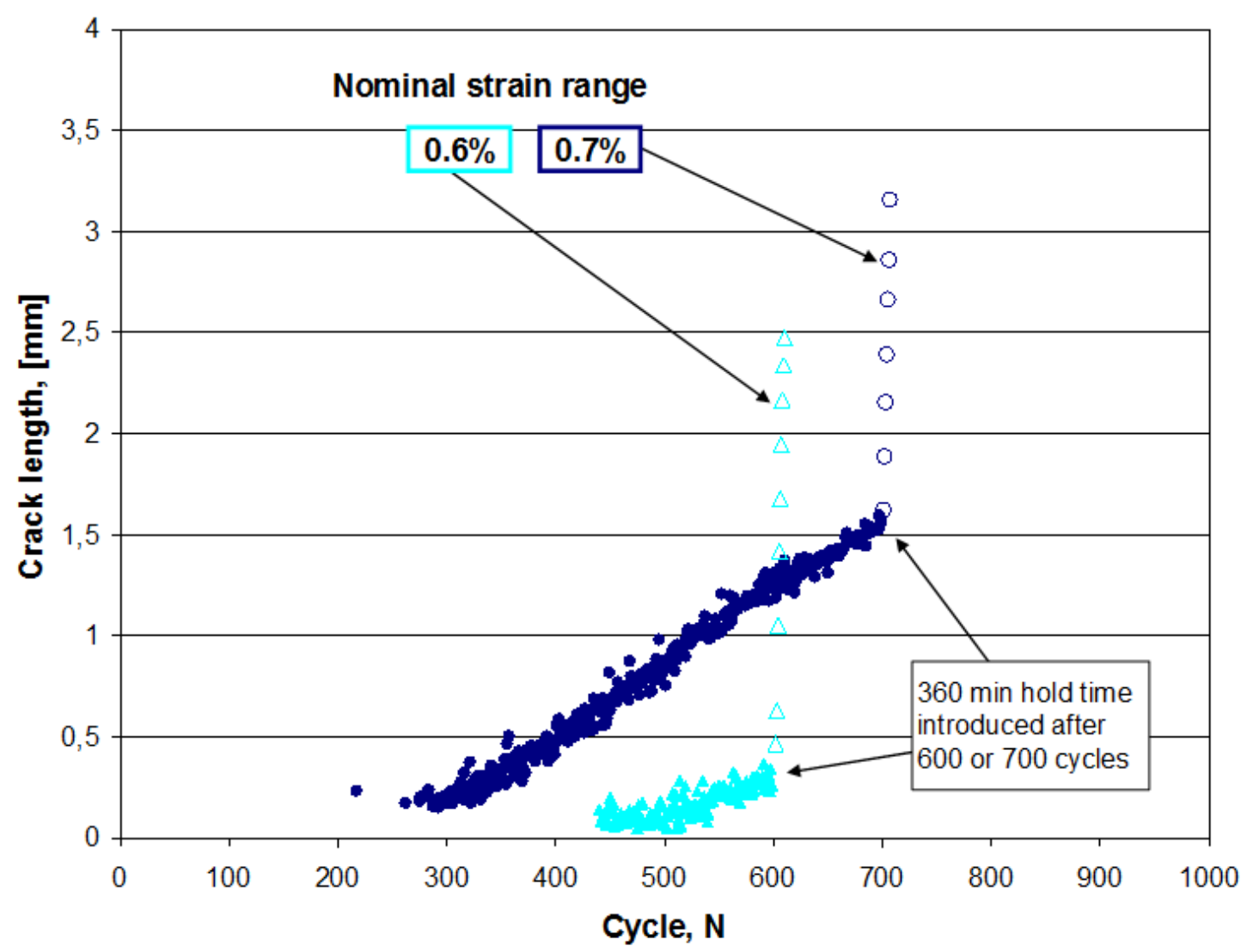

Figure 7: Crack length versus fatigue cycles for tests with the longest dwell time. The dwell time was changed from 0 min to 360 min after 700 cycles in the test with $0.7 \%$ nominal strain range and after 600 cycles in the test with $0.6 \%$ nominal strain range.

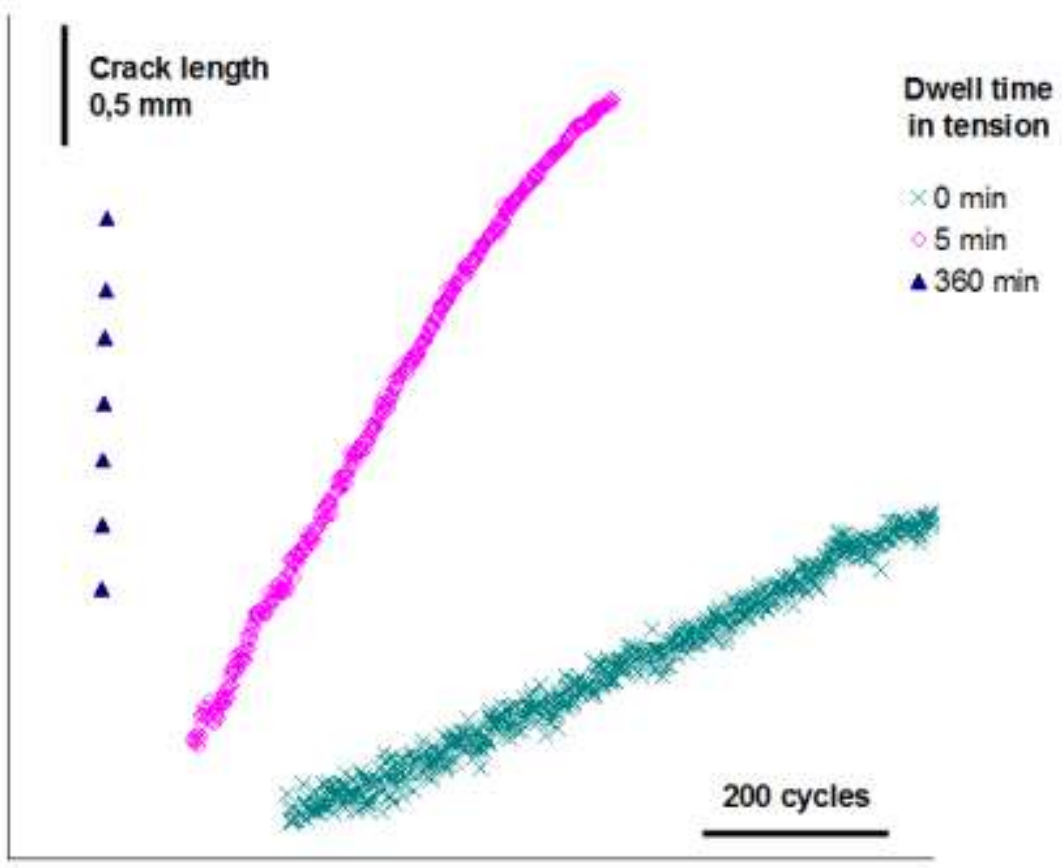

Figure 8: Crack propagation for tests with a constant nominal strain range of $0.7 \%$ and different dwell times. 


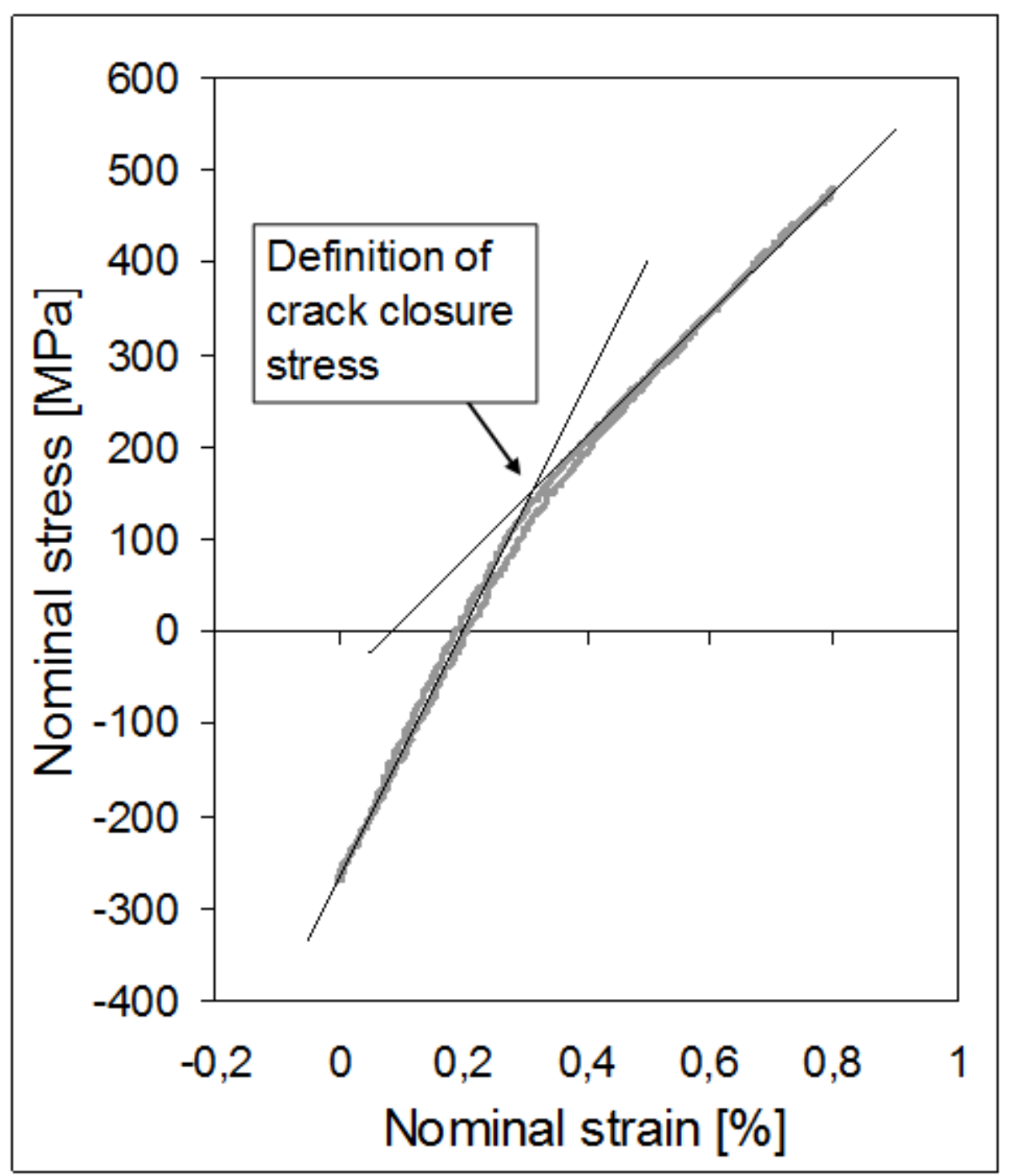

Figure 9: Definition of crack closure level

where $f(a)$ is the geometry function found by the FE analysis, $a$ is the crack length, $\sigma_{\max }^{\text {nom }}$ is the maximum nominal stress and $\sigma_{\text {close }}$ is the crack closure level for the corresponding crack length. The results can be seen in Figure [11] (a) and Figure [11] (b), respectively. A somewhat better correlation is obtained with the maximum stress intensity factor $K_{\max }$, especially for the test where a hold time was introduced at the maximum temperature. This is even more accentuated considering each test separately. As indicated in Figure [11] (a) and Figure [11] (b), a lower level of crack closure can be found in tests with dwell time compared to tests without hold time. This is further illustrated in Figure [12], showing crack closure levels for three tests with different dwell times at the same strain range levels. Furthermore, it also becomes evident that the difference in behavior with and without hold times cannot be explained by crack closure solely, since the crack closure level has already been taken into account into Figure [11] (a). 


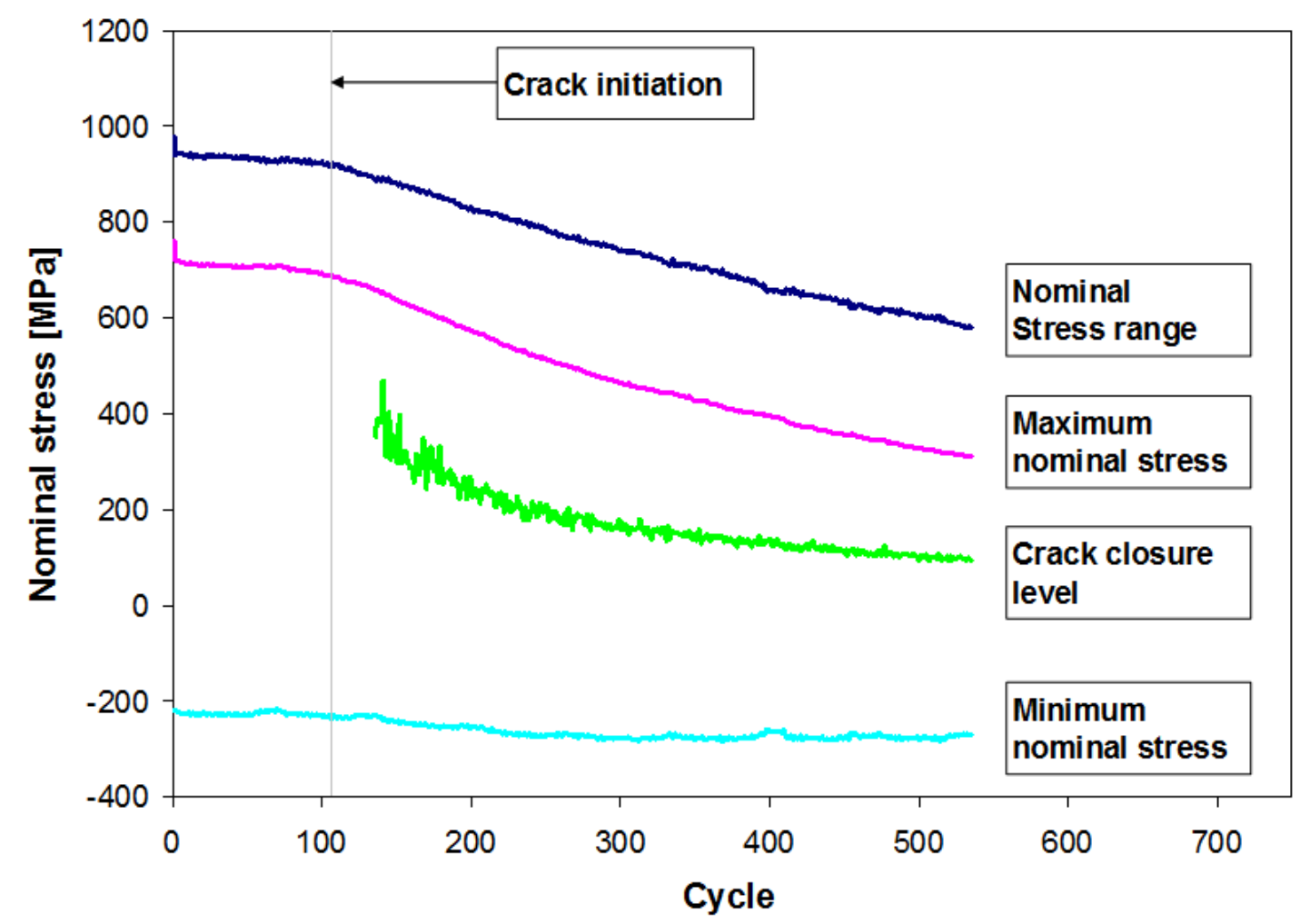

Figure 10: Evolution of nominal stresses during a test with a $0.8 \%$ strain range and a dwell time of $5 \mathrm{~min}$.
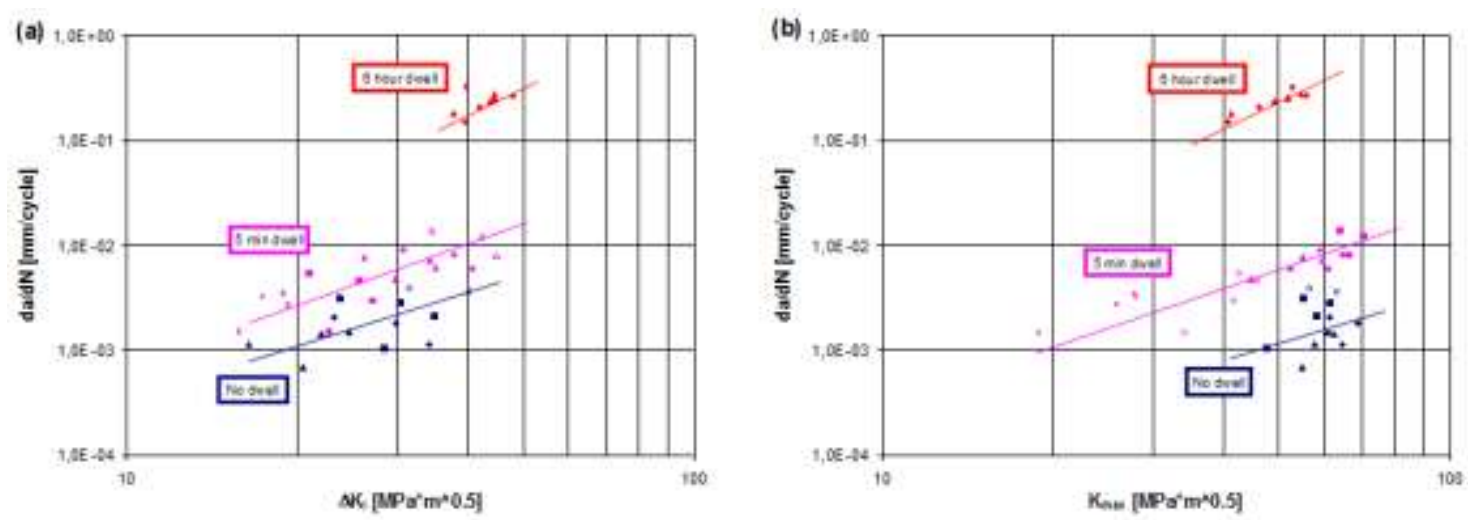

Figure 11: Crack propagation rates correlated against the stress intensity factor range $\Delta \mathrm{K}_{\mathrm{I}}$ and the maximum stress intensity factor $\mathrm{K}_{\max }$

\subsection{Fracture appearance}

The fracture surfaces after IP TMF testing with different lengths of the hold time at $550^{\circ} \mathrm{C}$ can be seen in Figure [13]. Apparently the amount of intercrystalline cracking increases with increasing length of the hold time. It also appears as if the amount of delta phase in the fracture surface increases with the amount of intercrystalline cracking.

A side view of the macroscopic fracture appearance of test no 9 which has a transition from no dwell to 6 hour dwell time at a crack length of approximately $1.7 \mathrm{~mm}$ is displayed in Figure [14]. In this picture one can see a clear change in the preferred crack propagation direction. While it is almost perpendicular to the loading direction when no 


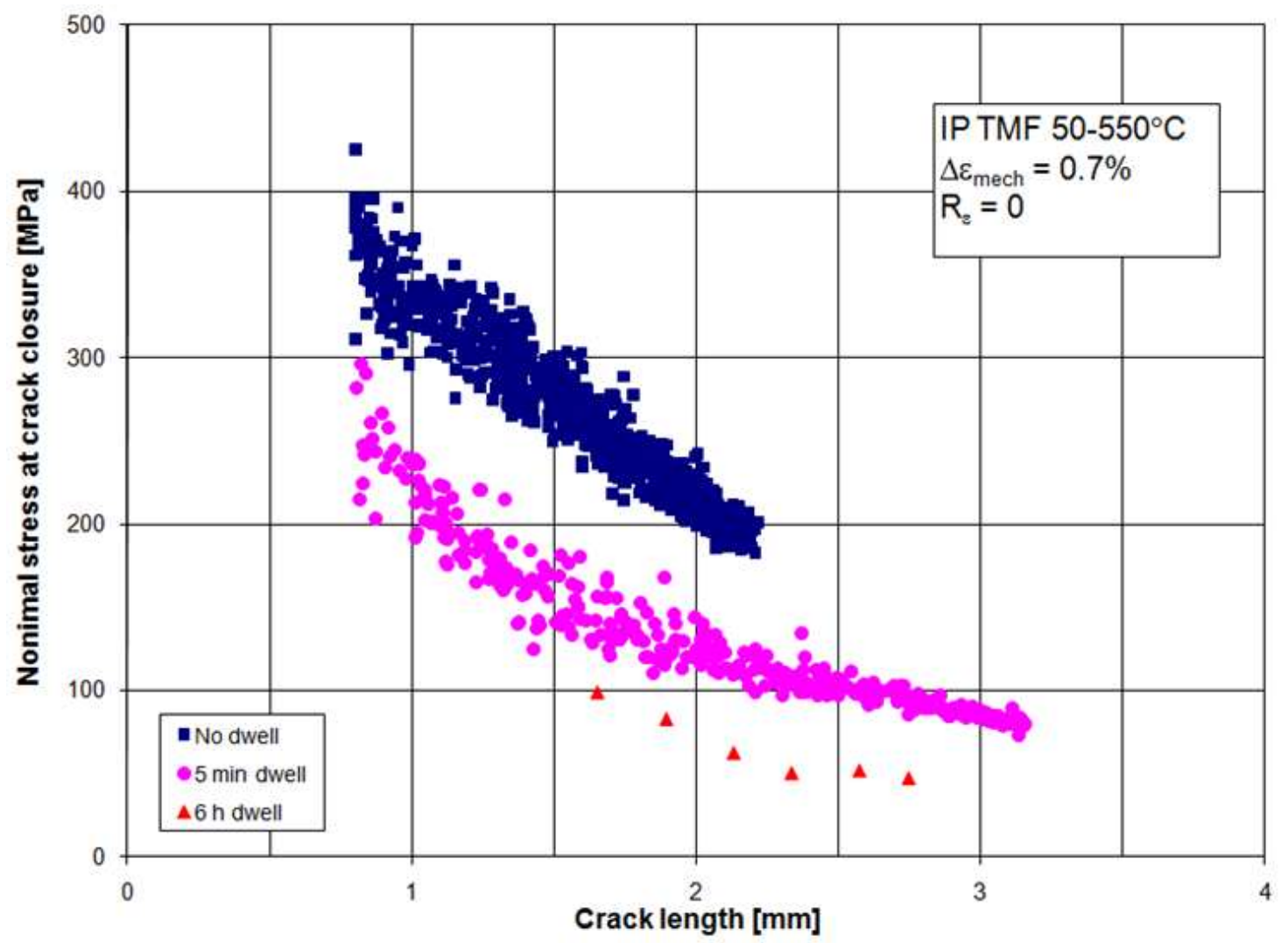

Figure 12: Showing crack closure levels for three different tests.
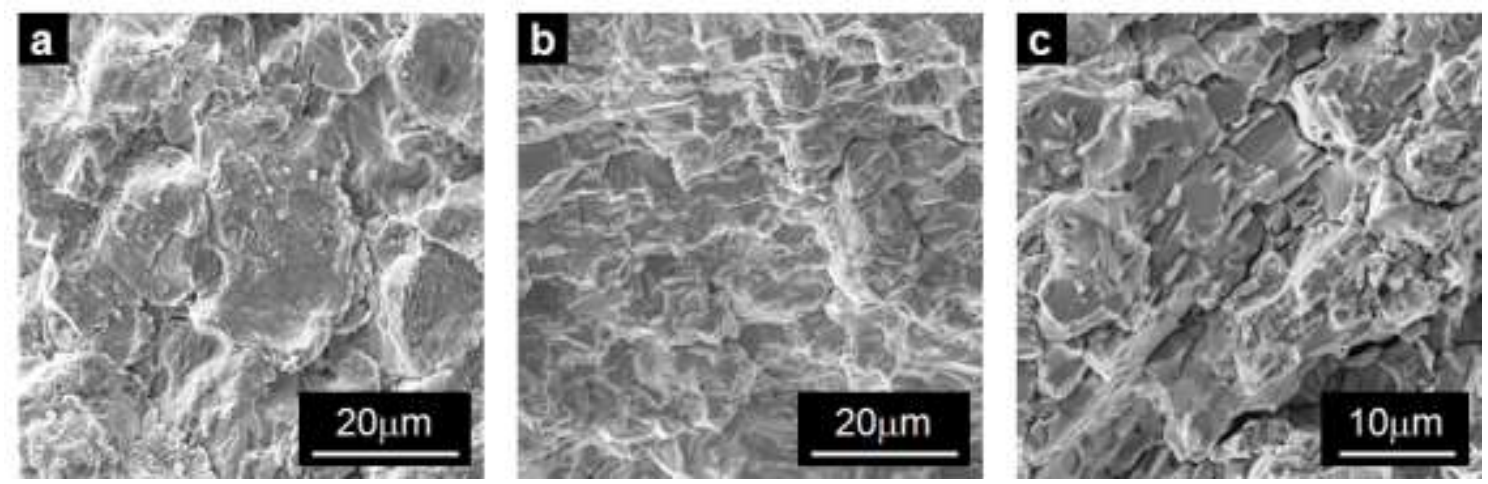

Figure 13: Fracture surface for TMF crack propagation tests with (a) no hold time, (b) 5 min hold time and (c) 6 hour hold time.

dwell time is applied, it immediately diverges into a $45^{\circ}$ direction when a 6 hour dwell time is applied. This behavior was found for both samples having a postponed dwell time of 6 hours and can also be seen in the SEM pictures in Figure [15], where the fracture appearance in a cross section view near the crack tip is displayed. It is to be noted that, although these diverging cracks do not grow in mode I, they are still plotted in Figure [11] and Figure [16] as functions of $\mathrm{K}_{\mathrm{I}}$. Furthermore, the crack lengths in these tests are the projected crack length. The $45^{\circ}$ deviation is a subject to further study. A final important observation that can be made with regard to Figure [15] is that the amount of plasticity around the crack is much higher when no hold time is applied. 


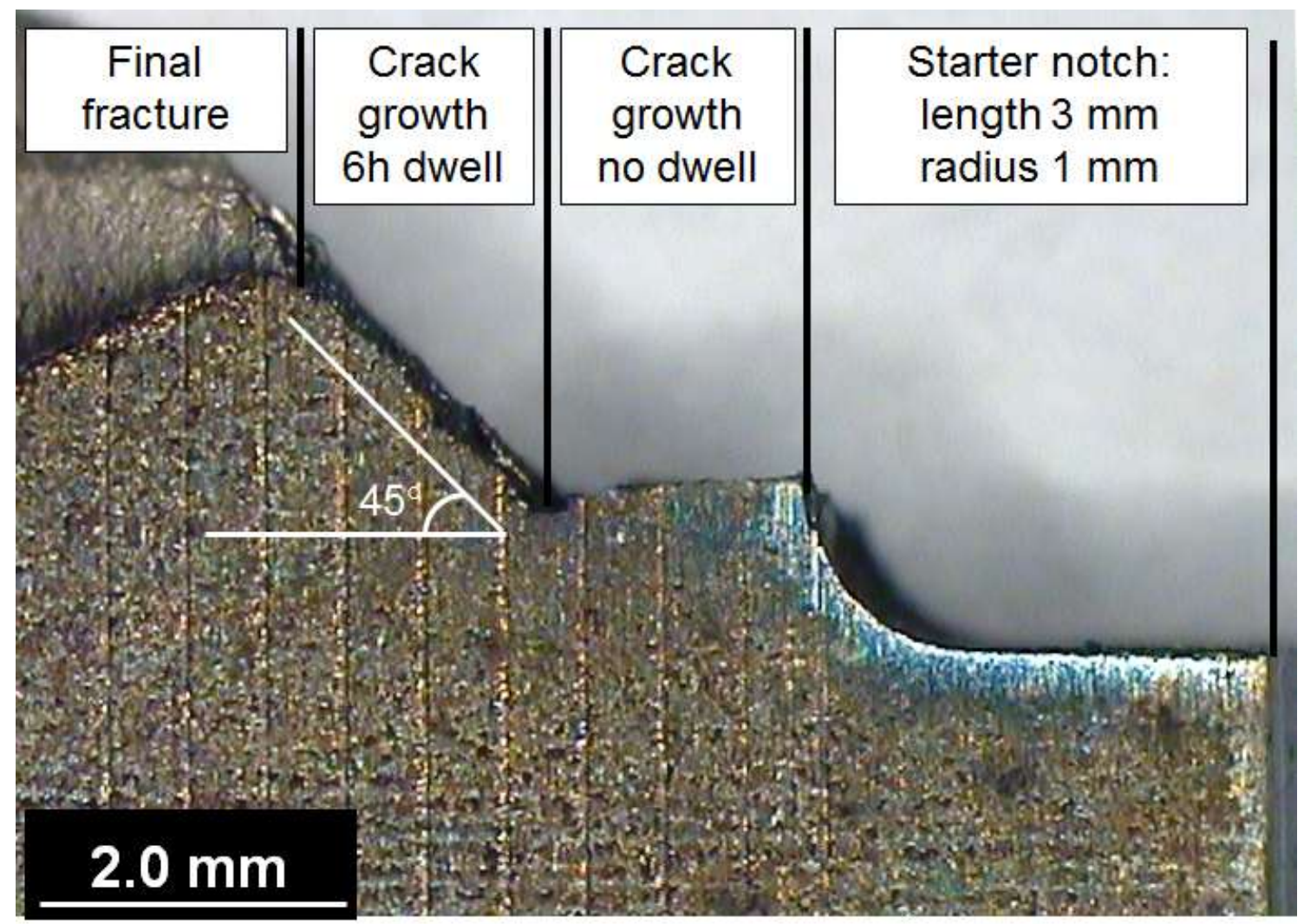

Figure 14: Side view of the macroscopic fracture appearance of test no 9 which have a transition from no dwell to 6 hour dwell at a crack length of approximately $1.7 \mathrm{~mm}$.
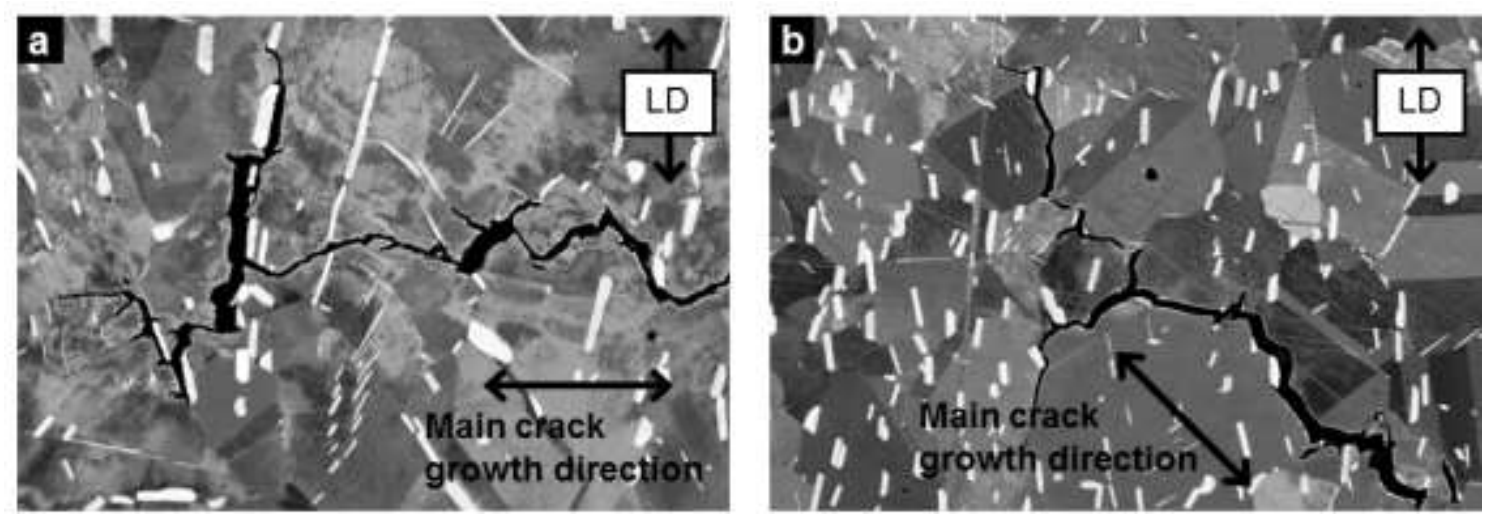

Figure 15: SEM pictures in backscatter mode showing the cross section of the crack tip for; (a) test no 3 with no dwell time and (b) test no 10 with 6 hour dwell time.

\section{Discussion}

\subsection{Correlation of da/dN to $\Delta K$ och $K_{\max }$}

The time-dependent crack growth rate (da/dt) of various metals has been correlated to several different crack-tip field parameters such as the crack opening displacement [19], the contour integral $J$ [20], the stress-intensity factor $K$ [20-22], the energy-rate-line integral $C^{*}$ [23-25] and the change of energy input rate with unit crack length increase $C_{\mathrm{t}}$ [26-28]. Generally, $C^{*}$ and $C_{\mathrm{t}}$ are more suitable for characterizing the creep crack growth rate in creep-ductile metals at high temperatures while $K$ is suitable for low or intermediate temperatures and also for creep brittle materials. From an engineering perspective it is preferable to use the stress intensity factor $K$ since the calculation of 

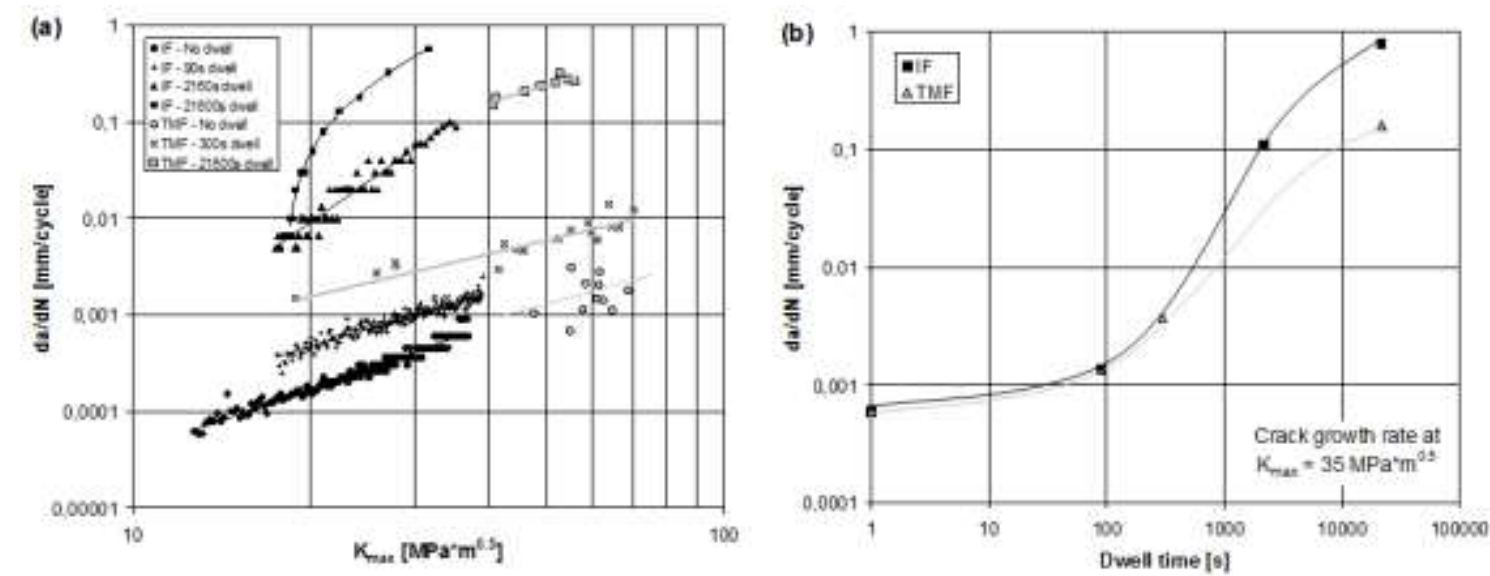

Figure 16: Comparison between isothermal (IF) fatigue crack growth at $550^{\circ} \mathrm{C}$ and IP$\mathrm{TMF}$ crack growth in the temperature range $50-550^{\circ} \mathrm{C}$. (a) crack growth rate as a function of maximum stress intensity factor, (b) crack growth rate as a function of dwell time for a stress intensity factor of $35 \mathrm{MPa}-\mathrm{m}^{0.5}$.

this parameter is often easier compared to the creep dependent parameters. For all tests conducted in this investigation, the specimen mechanical behaviour remained essentially elastic, which suggests that $K$ is a valid parameter. Several other investigations on precipitation-strengthened superalloys have also demonstrated that $K$ is a valid parameter for describing creep-fatigue crack growth at temperatures even higher than used in this study [29-31].

It is well known that the presence of a dwell time at maximum load in isothermal tests results in increased crack growth rates [29]. It has also been shown that the effect of dwell periods at higher $R$ values is greater than that at lower $R$ values [32], which indicates that it is not only $\Delta K$ and the length of the dwell time that governs the crack growth rate. Instead, the stress intensity factor applied during the hold time is an important parameter. Recent work has shown that this effect is not only attributed to traditional creep crack growth effects. Instead it has been noticed that the increase in crack length for each unloading and reloading are much larger for tests with dwell compared to tests without a dwell time [33]. In [33] it is shown that the time dependent crack growth during a dwell time is heavily retarded after each unloading and reloading and for tests with shorter hold times, the crack growth rate is totally dominated by the instantaneous crack growth during load reversal. Furthermore, longer dwell times will give larger crack growth during unloading and reloading compared to situations with shorter dwell times. However, if the hold time is long and temperature is high, despite the larger crack growth during unloading and reloading the time dependent crack growth during the hold time can be the most contributing factor to the total crack growth during the load sequence. As mentioned previously, the present work shows that the crack propagation rate during IP TMF loading correlates better with $\mathrm{K}_{\max }$ compared to $\Delta \mathrm{K}$ when dwell times are applied, see Figure [11]. Furthermore, the correlation between $\mathrm{K}_{\max }$ and crack growth rate da/dN is better for longer dwell times compared to shorter dwell times. From this observation one must draw the conclusion that the crack closure level has no significant effect on the fatigue crack growth at high temperature if extended hold times are applied in tension during the test or during the service cycle of real components. 


\subsection{Comparison to isothermal fatigue data}

The influence of dwell time on isothermal fatigue (IF) crack growth in Inconel 718 has been reported in previous studies by Gustafsson et. al [33-34]. In these IF experiments a $\mathrm{Kb}$-type specimen with a rectangular cross section and a semicircular crack was used under load control with an R-ratio of 0.05. Despite the differences with respect to temperature cycling, specimen geometry and control mode, good correlation can be found between the IF tests and the TMF tests when plotted against the maximum stress intensity factor $K_{\max }$, see Figure [16] (a). This is further illustrated in Figure [16] (b) where the crack propagation rates are plotted as a function of dwell time at $550^{\circ} \mathrm{C}$ for a constant maximum stress intensity factor $\mathrm{K}_{\max }=35 \mathrm{MPa} \cdot \mathrm{m}^{0.5}$. Some discrepancy between the IF tests and the TMF tests can perhaps be seen for the longest hold time (21600s) but this could be an effect of the difference in specimen geometry and the fact that the crack propagation in the TMF tests with this long hold time does not occur perpendicular to the loading direction, see Figure [14] and Figure [15]. In the case of the TMF specimen there is a through thickness crack while for the IF specimen there is a semi-circular surface crack as illustrated in Figure [17]. Most likely there is a propensity for mode II crack propagation also in the IF tests with the longest dwell time, but the semi-circular surface crack will have stronger geometrical constraints that will keep the crack growth direction perpendicular to the loading direction.
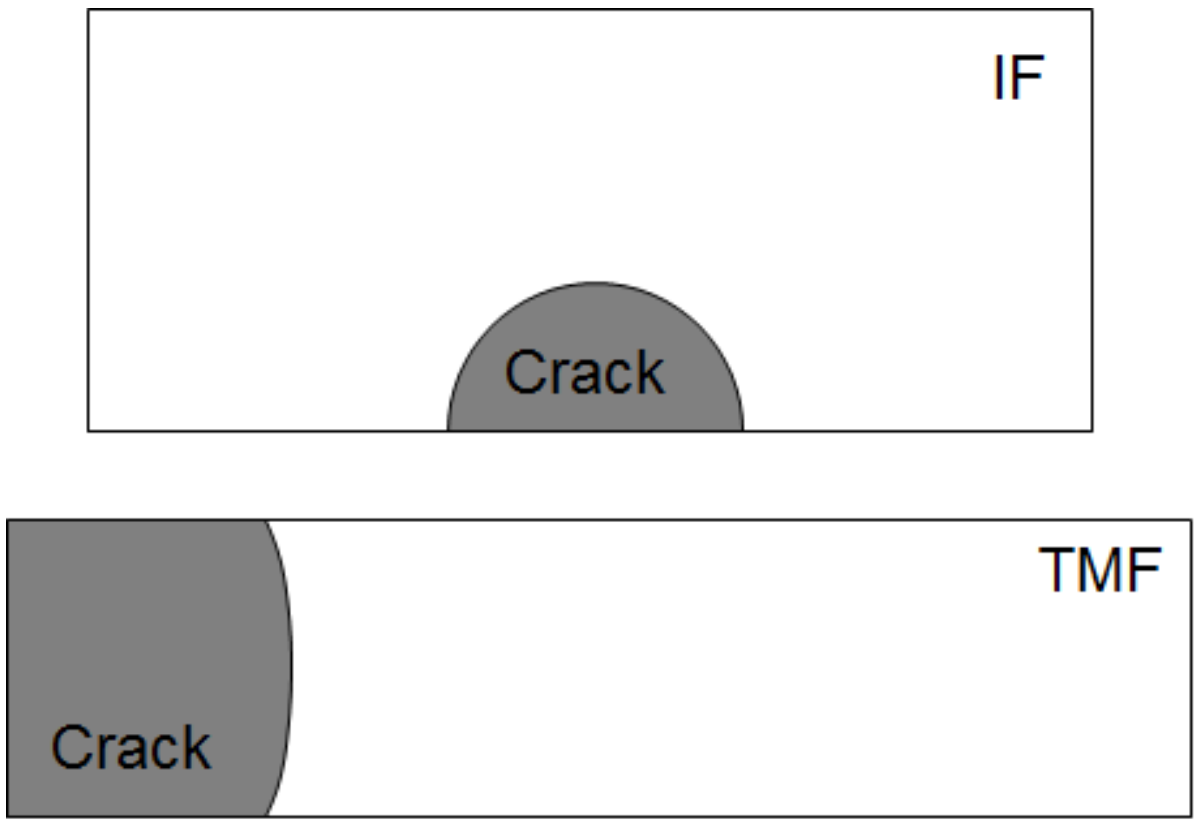

Figure 17: Schematic illustration of the difference in crack geometry between the IF and TMF test specimen.

\subsection{Effect of dwell time}

Today, the applicability of wrought fine grained polycrystalline nickel base superalloys such as Inconel 718 are in many situations limited by their susceptibility to fast intergranular cracking during extended hold times at high temperatures and high tensile stresses. Much of the early work assumed that the time dependence originated from the nature of deformation at the crack tip and the term creep fatigue was applied but it is 
now rather well established that the time dependent intergranular cracking of nickel based superalloys, under both sustained and cyclic loads, is dominated by environmental interactions at the crack tip [35]. The main damaging species that is always present is oxygen, but other more aggressive species most likely have a significant impact on the life of gas turbine discs [36]. However, this kind of intergranular cracking is not due to the formation of massive oxidation products along the grain boundaries. It can rather be described as a mechanism of "dynamic embrittlement" on a nanoscale, i.e. diffusion of elemental oxygen into highly stressed grain boundaries ahead of a growing crack, followed by decohesion [37]. The interaction of oxygen with the tip of a propagating crack is for obvious reasons extremely difficult to study due to the small scale of penetration. However, crack tip studies of for instance Inconel 718 have showed complex oxides of $\mathrm{Ni}, \mathrm{Cr}$ and $\mathrm{Fe}$, but also oxidation of niobium carbides has been reported [38]. Three distinct processes of intergranular embrittlement involving oxidation reactions have been confirmed experimentally. One of these, the oxidation of intergranular sulphides, results in elemental sulphur embrittlement and subsequent local decohesion under stress. The other two, oxidation of carbon to form carbon dioxide gas bubbles and oxidation of strong oxide formers to form intergranular internal oxides, results in a reduction of the local ability to accommodate stress concentrations associated with sliding grain boundaries. The present study supports the idea that the deformation close to the crack tip at least partly occur by grain boundary sliding. Evidence of this can be found in Figure [15] (b) and by the fact that the crack propagation in the tests with the longest dwell time occur along those grain boundaries which experience highest shear stress (i.e. grain boundaries oriented $45^{\circ}$ from the loading direction).

\subsection{On crack propagation under TMF conditions}

The current work clearly indicates a good correlation between isothermal tests conducted in stress control and the in-phase thermo-mechanical fatigue tests conducted in mechanical strain control. This indicates that the damage process must be strongly connected to the conditions during the dwell time. However, as mentioned earlier, this is not necessarily due to crack extension occurring during the dwell time. As for the IF tests reported by Gustafsson et. al [33-34], it is possible that an important effect of the dwell time in the TMF tests is an increase in crack extension during the unloadingreloading sequence between the dwell times. In the IF tests this was confirmed by continuous potential drop measurements. In the current work no such measurements have been carried out, but indirect evidence of the phenomenon described above can be found in the stiffness measurements conducted above the crack closure stress during both the loading and unloading sequence for one of the tests with 360 min dwell time, see Figure [18]. One can see that despite the extended dwell time and the very high crack propagation rate in this test, the specimen stiffness measured just after the hold time is higher compared to that measured prior to the dwell time. However, even more marked is that the stiffness in the next loading sequence has decreased significantly which clearly indicates significant crack propagation due to the unloading/reloading process. The increase in stiffness during the hold time can perhaps be explained by stress relaxation at the crack tip. 


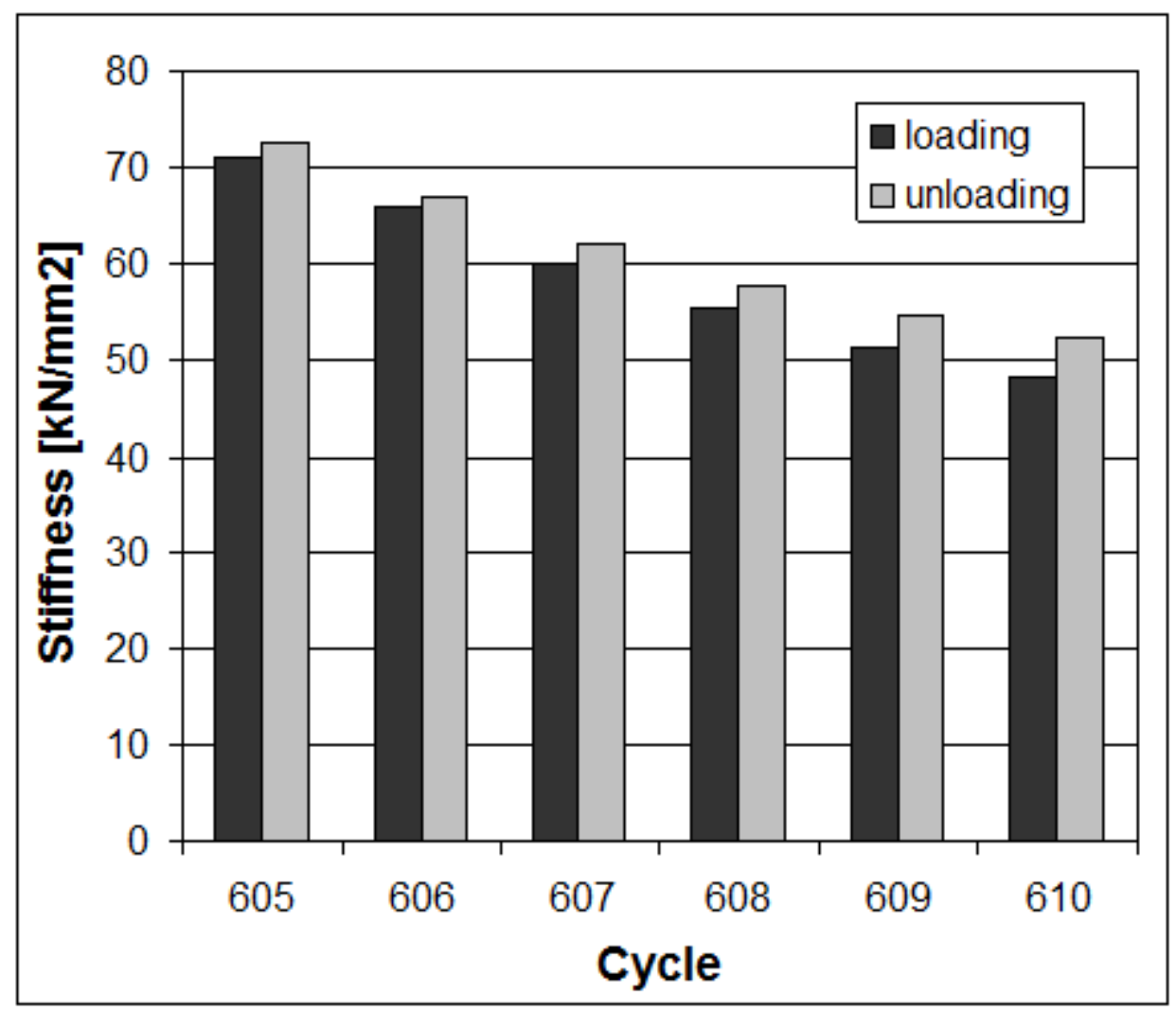

Figure 18: Specimen stiffness measured above the crack closure stress during both the loading and unloading sequence in one of the IP-TMF tests with 21600s dwell time.

\subsection{Damaged zone}

Despite the fact that a significant part of the crack extension occurs during the unloading-reloading sequence for which the temperature is constant at $550^{\circ} \mathrm{C}$ in the IF test and cycled from $550^{\circ} \mathrm{C}$ down to $50^{\circ} \mathrm{C}$ and back again in the TMF test, good correlation in crack propagation rate is found for the two types of tests. The interpretation of this must be that a damaged zone develops ahead of the crack tip during the dwell time, see [33], and this zone is sensitive for cracking during the load reversal. Regardless of which of the embrittling mechanisms described above that are active, it is only in a limited volume of the material in front of and around the crack tip; this region of embrittled material is what is referred to as the damaged zone. This concept can be useful explanatory model for the mechanisms and phenomena discussed above and also a good basis for fatigue crack propagation modelling.

The crack extension during the load reversal is mainly dependent on the size of the damaged zone rather than on the load and temperature conditions prevailing during the load reversal itself. This also explains why there is a good correlation between the IF tests and the TMF tests when they are plotted as a function of $K_{\max }$ applied during the dwell time. The assumption that the crack extension during a load reversal in a hold time test mainly depends on the size of the damaged zone ahead of the crack tip actually indicates a possibility to use isothermal fatigue crack growth data not only to predict the in-phase TMF cycle as considered in this work, but also any type of transient or out-ofphase TMF cycle. Further work is however needed in order to characterize the size of 
the damaged zone as a function of the length of the dwell time, the temperature and the stress intensity factor.

\section{Summary and Conclusions}

In-phase TMF crack growth testing with different lengths of the dwell time at the maximum temperature of $550^{\circ} \mathrm{C}$ has been conducted on Inconel 718 specimens. The evaluation of the experiments and the comparison to iso-thermal fatigue crack growth data has lead to the following conclusions:

- The crack growth rate and the amount of intercrystalline cracking increases with increasing length of the hold time.

- TMF tests with different mechanical strain ranges show a good correlation when plotted against the stress intensity factor applied during the dwell time.

- Good correlation between iso-thermal fatigue crack growth tests and TMF crack growth tests are found when the crack growth rates are plotted as a function of the stress intensity factor applied in the dwell time.

- These findings fit well with the concept of a damaged zone evolving ahead of the crack tip during the hold time. The size of this damaged zone will control the crack propagation rate and therefore it does not matter if the load is cycled under isothermal or TMF conditions.

\section{Acknowledgements}

This research has been funded by the Swedish Energy Agency, Siemens Industrial Turbomachinery AB, Volvo Aero Corporation, and the Royal Institute of Technology through the Swedish research program TURBO POWER, the support of which is gratefully acknowledged. The authors would like to thank Kjell Simonsson, Sten Johansson and Sören Sjöström for valuable discussion, Jan Kanesund for microscopy work, Bo Torstenfelt for making the Trinitas software available, Babak Sharifimajd for help with the FE-modelling and Bo Skoog for conducting the isothermal fatigue tests, all at Linköping University. Krystina Stiller and Leif Viskari at Chalmers University of Technology and Magnus Hörnqvist at Volvo Aero Corporation are also acknowledged for fruitful discussions.

\section{References}

[1] C.A. Rau, A.E. Gemma, G.R. Leverant, Thermal-mechanical fatigue crack propagation in nickel- and cobalt-base superalloys under various straintemperature cycles, Fatigue at elevated temperatures. ASTM STP 520 (1973) $166-78$.

[2] G.R. Leverant, T.E. Strangman, B.S. Langer, Parameters controlling the thermal fatigue properties of conventionally-cast and directionally-solidified turbine alloys, In: Int symp on Superalloys seven springs, September 12-15 (1976) 28595.

[3] A.E. Gemma, B.S. Langer, G.R. Leverant, Thermo-mechanical fatigue crack propagation in an anisotropic (directionally solidified) nickel-base superalloy. Therm Fatigue Mater Compon, ASTM STP 612 (1976) 199-213. 
[4] M. Okazaki, T. Koizumi, Effect of Strain Wave Shape on Thermal-Mechanical Fatigue Crack Propagation in a Cast Low-Alloy Steel, J. Eng. Mater. Tech. 105 (1983) 81-87.

[5] M. Okazaki and T. Koizumi, Crack propagation of steels during low cycle thermal-mechanical and isothermal fatigue at elevated temperatures, Metall. Trans. A. 14 (1983) 1641-1648.

[6] R.M. Pelloux, N. Marchand, Thermal-Mechanical Fatigue Behavior of NickelBase Superalloys, NASA-CR-175048, 1986.

[7] K.S. Kim, R.H. Vanstone, S.N. Malik, J.H. Laflen, Elevated temperature crack growth, NASA-CR-182247, 1988.

[8] K.S. Kim, R.H. Van Stone, Elevated Temperature Crack Growth, NASA-CR189191, 1992.

[9] K.S. Kim, R.H. Van Stone, Crack growth under thermo-mechanical and temperature gradient loads, Eng. Fract. Mech. 58 (1997) 133-147.

[10] H. Sehitoglu, Crack-growth studies under selected temperature-strain histories, Eng. Fract. Mech. 26 (1987) 475-489.

[11] M.L. Heil, T. Nicholas, and G.K. Haritos, Crack growth in alloy 718 under thermal-mechanical cycling, in: H. Sehitoglu and S.Y. Zamrik (Eds.) Thermal stress, material deformation, and thermo-mechanical fatigue, ASME PVP. 123 (1987) 23-29.

[12] S. Mall, T. Nicholas, J.J. Pernot, D.G. Burgess, Crack growth in a titanium aluminide alloy under thermal mechanical cycling, Fatigue Fract. Mater. Struct. 14 (1991) 79-87.

[13] M.L. Heil, Crack growth in alloy 718 under thermal-mechanical cycling, Dissertation: Factulty of the School of Engineering of the Air Force Institute of Technology, Air University, 1986.

[14] L. Jacobsson, C. Persson, S. Melin, Thermo-mechanical fatigue crack propagation experiments in Inconel 718, Int. J of Fatigue. 31 (2009) 1318-1326.

[15] Hähner P, Affeldt E, Beck T, Klingelhöffer H, Loveday M, Rinaldi C, editors. Validated code-of-practice for strain-controlled thermo-mechanical fatigue testing. EUR $22281 \mathrm{EN}$ - DG JRC - Institute for Energy, Scientific and Technical Research series, ISBN 92-79-02216-4, Luxembourg; 2006.

[16] J. Moverare, S. Johansson, R.C. Reed, Deformation and damage mechanisms during thermal-mechanical fatigue of a single-crystal superalloy, Acta Mater. 57 (2009) 2266-2276.

[17] ASTM E 647-05. Standard test method for measurement of fatigue crack growth rates. Annual book of ASTM standards. (2007) 03.01.

[18] http://www.solid.iei.liu.se/Offered_services/Trinitas/index.html

[19] J.R. Haigh, The mechanisms of macroscopic high temperature crack growth part I: Experiments on tempered CrMoV steels, Mater. Sci. Eng. 20 (1975) 213-223.

[20] K. Sadananda, P. Shahinian, Creep crack growth in alloy 718, Metall. Trans. A 7 (1977) 439-449. 
[21] C.B. Harrison, G.N. Sandor, High-temperature crack growth in low-cycle fatigue, Eng. Fract. Mech. 3 (1971) 403-420.

[22] M.J. Siverns, A.T. Price, Crack propagation under creep conditions in a quenched 2.25 Chromium 1 molybdenum steel, Int. J. Fract. 9 (1973) 199-207.

[23] J.D. Landes, J.A. Begley. In: Mechanics of crack growth. A Fracture Mechanics Approach to Creep Crack Growth, ASTM STP 590 (1976) 128.

[24] K.M. Nikbin, G.A. Webster, C.E. Turner, Relevance of Nonlinear Fracture Mechanics to Creep Cracking, In: Cracks and fracture, ASTM STP 601 (1976) 47.

[25] A. Saxena, Evaluation of $C^{*}$ for the Characterization, In: Fracture mechanics: twelfth conference, ASTM STP 700 (1980) 131.

[26] A. Saxena, Creep Crack Growth under Non-Steady-State Conditions, In: Fracture mechanics: seventeenth conference, ASTM STP 905 (1986) 185.

[27] Saxena, Creep crack growth in high temperature ductile materials, Eng. Fract. Mech. 40 (1991) 721-736.

[28] P.K. Liaw, A. Saxena, J. Schaefer, Estimating remaining life of elevatedtemperature steam pipes-Part I. Materials properties, Eng. Fract. Mech. 32 (1989) 675-708.

[29] J.P. Pédron, A. Pineau, The effect of microstructure and environment on the crack growth behaviour of Inconel 718 alloy at $650{ }^{\circ} \mathrm{C}$ under fatigue, creep and combined loading, Mater. Sci. Eng. 56 (1982) 143-156.

[30] M.S.G. Krishna, A.M Sriramamurthy, V.M. Radhakrishnan, Creep crack growth behavior at $1033 \mathrm{~K}$ of directionally solidified CM 247 LC - A cast nickel-base superalloy, Scripta Mater. 32 (1996) 1325-1330.

[31] R.C. Donath, T. Nicholas, L.S. Fu, An experimental investigation of creep crack growth in IN100, In: Fracture mechanics: thirteenth conference. ASTM STP 743 (1981) 186.

[32] L.A. James, The effect of grain size upon the fatigue-crack propagation behavior of alloy 718 under hold-time cycling at elevated temperature, Eng. Fract. Mech. 25 (1986) 305-314.

[33] D. Gustafsson, J.J. Moverare, S. Johansson, K. Simonsson, M. Hörnqvist, T. Månsson, S. Sjöström, Influence of a damaged zone on the fatigue crack growth behaviour of Inconel 718 with high temperature hold times, Submitted for publiaction.

[34] D. Gustafsson, J.J. Moverare, S. Johansson, M. Hörnqvist, K. Simonsson, S. Sjöström, B. Sharifimajd, Fatigue crack growth behaviour of Inconel 718 with high temperature hold times, Procedia Engineering. 2(1) (2010) 1095-1104.

[35] D.A. Woodford, Gas phase embrittlement and time dependent cracking of nickel based superalloys, Energy Materials. 1 (2006) 59-79.

[36] J.P. Beckman, D.A. Woodford, Gas phase embrittlement of nickel by sulfur, Metall. Mater. Trans. A 21 (1990) 3049-3061.

[37] Ph. E.-G. Wagenhuber, V.B. Trindade, U. Krupp, The role of oxygen-grainboundary diffusion during intercrystalline oxidation and intergranular fatigue 
crack propagation in alloy 718, in: E. A. Loria (ed), Proc. Superalloys 718, 625, 706 and Various Derivatives, TMS. (2005) 591-600.

[38] M. Gao, D. J. Dwyer and R. P. Wei, Chemical and Microstructure Aspects of Creep Crack Growth in Inconel 718 Alloy, in: A. Loria (ed), Proc. Superalloys 718, 625, 706 and Various Derivatives, TMS. (1994) 581-592.

Table 1: Summary of crack propagation rates for all tests

\begin{tabular}{|ccc|cccc|}
\hline \multirow{2}{*}{$\begin{array}{c}\text { Test } \\
\text { No }\end{array}$} & $\begin{array}{c}\text { Nominal } \\
\text { strain range }\end{array}$ & $\begin{array}{c}\text { Dwell } \\
\text { time } \\
\end{array}$ & {$[\%]$} & \multicolumn{4}{|c|}{$\begin{array}{c}\text { Crack propagation rate for different crack lengths } \\
{[\mathrm{mm} / \text { cycle] }}\end{array}$} \\
\cline { 4 - 7 } & {$[\mathrm{min}]$} & $0.5 \mathrm{~mm}$ & $1.0 \mathrm{~mm}$ & $2.0 \mathrm{~mm}$ & $3.0 \mathrm{~mm}$ \\
\hline 1 & 0.7 & 0 & $2.06 \mathrm{e}-3$ & $1.81 \mathrm{e}-3$ & $1.13 \mathrm{e}-3$ & - \\
2 & 0.6 & 0 & $3.10 \mathrm{e}-3$ & $2.81 \mathrm{e}-3$ & $2.12 \mathrm{e}-3$ & $1.04 \mathrm{e}-3$ \\
3 & 0.5 & 0 & $1.15 \mathrm{e}-3$ & $1.43 \mathrm{e}-3$ & $1.49 \mathrm{e}-3$ & $6.87 \mathrm{e}-4$ \\
\hline 4 & 1.0 & 5 & $1.40 \mathrm{e}-2$ & $1.23 \mathrm{e}-2$ & $8.09 \mathrm{e}-3$ & - \\
5 & 0.8 & 5 & $9.05 \mathrm{e}-3$ & $8.16 \mathrm{e}-3$ & $6.01 \mathrm{e}-3$ & - \\
6 & 0.7 & 5 & $7.68 \mathrm{e}-3$ & $7.20 \mathrm{e}-3$ & $6.13 \mathrm{e}-3$ & $4.82 \mathrm{e}-3$ \\
7 & 0.5 & 5 & $5.44 \mathrm{e}-3$ & $4.66 \mathrm{e}-3$ & $2.98 \mathrm{e}-3$ & $1.50 \mathrm{e}-3$ \\
8 & 0.4 & 5 & $3.24 \mathrm{e}-3$ & $3.49 \mathrm{e}-3$ & $2.72 \mathrm{e}-3$ & $1.49 \mathrm{e}-3$ \\
\hline $9: 1$ & 0.7 & 0 & $3.93 \mathrm{e}-3$ & $3.61 \mathrm{e}-3$ & - & - \\
$9: 2$ & 0.7 & 360 & - & - & $2.73 \mathrm{e}-1$ & $1.92 \mathrm{e}-1$ \\
10 & 0.6 & 360 & $3.62 \mathrm{e}-1$ & $3.30 \mathrm{e}-1$ & $2.26 \mathrm{e}-1$ & - \\
\hline
\end{tabular}

